\title{
Profil 10 besar kasus di Instalasi Gawat Darurat Bedah RSUP Prof. Dr. R. D. Kandou periode Januari - Desember 2015
}

\author{
${ }^{1}$ Dwika T. Takaendengan \\ ${ }^{2}$ P. A. V. Wowiling \\ ${ }^{2}$ Angelica M. J. Wagiu
}

\author{
${ }^{1}$ Kandidat Skripsi Fakultas Kedokteran Universitas Sam Ratulangi Manado \\ ${ }^{2}$ Bagian Bedah Fakultas Kedokteran Universitas Sam Ratulangi Manado \\ Email: dwikattakaendengan@yahoo.com
}

\begin{abstract}
Emergency cases, especially in surgery field, are still a major problem globally, therefore, health centers have to provide a better preparation to face such cases. This was a retrospective descriptive study. This study was aimed to obtain the profile of the 10 major cases in emergency department of surgery from January to December 2015 at Prof Dr. R. D. Kandou General Hospital. The results showed that the case distribution was predominated by non-traumatic case $(70.13 \%)$, males $(64.45 \%)$, and age group of 45-64 years (33.05\%). The major cases registered in Emergency Department of Surgery was 1) epidural haematome (3.55\%), followed by 2) subarachnoid haemorhage $(2.45 \%)$; 3) injuries of thorax and intrathoracal organs $(1.95 \%)$; 4) appendicitis $(1.89 \%) ; 5)$ fractures of the shoulder and upper arm (1.68\%); 6) sepsis $(1.51 \%)$; 7) fracture of femur $(1.45 \%) ; 8)$ injury of abdomen and intraabdominal organs $(1.43 \%) ; 9)$ hernia inguinalis $(1.18 \%)$; and 10) paralytic ileus and intestinal obstruction $(1.12 \%)$. Conclusion: The majority of cases were males, aged 45-65 years, and non-traumatic cases,.
\end{abstract}

Keywords: Emergency Department, surgery, major case

\begin{abstract}
Abstrak: Kasus gawat darurat khususnya di bidang ilmu bedah, masih merupakan masalah global. Oleh karena itu di berbagai pusat kesehatan yang telah mengetahui tingkat kejadian kasus kegawatdaruratan spesifik harus melakukan persiapan lebih baik. Jenis penelitian ialah deskriptif retrospektif untuk mendapatkan profil 10 besar kasus di Instalasi Gawat Darurat Bedah RSUP Prof Dr. R. D. Kandou periode Januari-Desember 2015. Hasil penelitian menunjukkan distribusi terbanyak ialah kasus non-trauma $(70,13 \%)$, jenis kelamin laki-laki $(64.45 \%)$ dan usia $45-64$ tahun $(33,05 \%)$. Penyakit terbesar tercatat di Instalasi Gawat Darurat Bedah ialah: 1) epidural hematom $(3.55 \%) ; 2)$ perdarahan subaraknoid $(2,45 \%)$; 3) cedera dada dan organ dalam dada $(1,95 \%) ; 4)$ apendisitis $(1,89 \%)$; 5) fraktur bahu dan lengan atas $(1,68 \%) ; 6)$ sepsis $(1,51 \%) ; 7)$ fraktur femur $(1,45 \%) ; 8)$ cedera perut dan organ dalam perut $(1,43 \%)$; 9) hernia inguinalis $(1,18 \%)$; dan 10$)$ ileus paralitik dan obstruksi intestinal $(1,12 \%)$. Simpulan: Pada studi ini, mayoritas kasus ialah laki-laki, usia 45-64 tahu, dan kasus non trauma.
\end{abstract}

Kata Kunci:Instalasi gawat darurat, bedah, kasus tersering

Dalam dunia kesehatan terdapat banyak kondisi yang membuat timbulnya masalah. Salah satunya ialah kondisi kegawatdaruratan. Kegawatdaruratan merupakan suatu keadaan kritis yang mendadak atau tidak disangka-sangka yang dapat mengancam jiwa dimana keadaan akhir pasien bergantung pada pemilihan keputusan dalam ukuran yang lebih dari biasanya. $^{1-2}$ Ini dapat disebabkan oleh berbagai faktor antara lain adalah infeksi, trauma, gangguan keseimbangan cairan dan elektrolit. ${ }^{3}$ Lebih khususnya dalam bidang ilmu bedah kasus gawat darurat merupakan suatu kondisi medis yang perlu diperhatikan. Kasus gawat darurat 
ditangani awal di instalasi gawat darurat rumah sakit dan sering dikelompokkan dalam berbagai kategori seperti umur, pekerjaan, dan sebagainya untuk mempermudah pencatatan. ${ }^{4-6}$

Angka kunjungan kasus kegawatdaruratan di dunia memiliki variasi dalam jumlah kasus pada pada berbagai pusat kesehatan di berbagai negara. Berdasarkan suatu observasi yang dilakukan oleh Wier $^{7}$ tercatat lebih dari 120 juta kasus kegawatdaruratan pada tahun 2009 di Amerika. Angka ini mengalami peningkatan dari tahun 1991 sebanyak 44\% hingga tahun $2010{ }^{8}$ Di Inggris tercatat sebanyak 41 juta kasus kegawatdaruratan dalam periode tahun 2010 hingga 2013 berdasarkan suatu observasi yang dilakukan oleh Quality Watch Research Program, ${ }^{9}$ sedangkan di Jepang berdasar-kan data observasi dari Katayama et al. ${ }^{10}$ tercatat sekitar 2,6 juta kasus terjadi pertahun di kota Osaka.

Di Indonesia sendiri angka kejadian kasus kegawatdaruratan nasional belum terangkum sepenuhnya. Salah satu faktor yang dapat mempersulit pengumpulan data bisa berasal dari luas daerah Indonesia dan jumlah pusat kesehatan yang tersebar di berbagai daerah. Beberapa contoh angka kejadian kasus kegawatdaruratan di Indonesia diambil dari laporan data Pedoman Nasional Pelayanan Kedokteran dimana tercatat RSUD $\mathrm{dr}$ Soetomo Surabaya terdapat lebih dari 80.000 kunjungan pada tahun 2010 dan lebih dari 10.000 kasus kegawatdaruratan trauma di IGD RSU Sanglah Denpasar pada tahun yang sama yang sebagian besar kasus ditangani Bagian Bedah Kegawatdaruratan. ${ }^{11}$

Perbedaan angka yang signifikan dari beberapa contoh tersebut dapat dipengaruhi oleh berbagai macam faktor antara lain adalah lingkungan, teknologi dan masyarakat. ${ }^{12}$ Unsur-unsur lain yang dapat berpengaruh berupa masalah pendanaan dan teknik pengumpulan data. Faktorfaktor tersebut memiliki perbedaan yang terlihat jelas jika dilakukan perbandingan antara negara maju dan berkembang. ${ }^{13}$

Dampak dari pengetahuan akan tingkat kejadian kasus kegawatdaruratan ini adalah peningkatan pelayanan kesehatan di tempat terkait dimana persiapan dapat dilakukan secara lebih terarah dan pencegahan pada populasi yang tepat. Secara tidak langsung keadaan ini juga dapat membantu dalam penyusunan anggaran kesehatan daerah terkait, pengaturan sistim pelayanan daerah, pengembangan ilmu pengetahuan khususnya dalam ilmu bedah kegawatdaruratan dan lain sebagainya. Akhirnya semua dampak ini dapat meningkatkan kualitas kesehatan daerah maupun kesejahteraan masyarakat. ${ }^{14}$

Berdasarkan uraian di atas, penulis tertarik untuk meneliti mengenai profil kasus-kasus terbesar di Instalasi Gawat Ddarurat di rumah sakit di daerah penulis.

\section{METODE PENELITIAN}

Jenis penelitian ini ialah deskriptif retrospektif yang dilaksanakan di Bagian Rekam Medik RSUP Prof Dr. R. D. Kandou Manado pada bulan SeptemberNovember 2016. Populasi ialah pasien yang tercatat pernah dirawat di ruang Instalasi Gawat Darurat rumah sakit dan sampel merupakan pasien yang pernah dirawat dan mendapatkan terapi dari bagian bedah pada periode Januari hingga Desember tahun 2015 yaitu sebanyak 3379 pasien. Variabel penelitian yaitu usia, jenis kelamin dan penanganan lanjut yang dilakukan. Pengambilan data dilakukan dengan cara telaah rekam medik dan catatan registrasi pasien.

\section{HASIL PENELITIAN}

Data penelitian diambil berupa populasi sebanyak 3379 kasus. Dilihat dari karakteristik jenis kelamin, laki-laki merupakan pasien terbanyak yaitu sebanyak 2178 pasien $(64,45 \%)$ (Tabel 1).

Dilihat dari karakteristik usia, terbanyak ialah 45-64 tahun yaitu sebanyak 1117 pasien $(33,05 \%)$ (Tabel 2).

Dilihat dari karakteristik jenis kasus, terbanyak adalah kasus non trauma yaitu sebanyak 2370 pasien $(70,13 \%)$ (Tabel 3). 
Tabel 1. Karakteristik populasi menurut jenis kelamin

\begin{tabular}{ccc}
\hline Jenis kelamin & Jumlah $(\mathbf{n})$ & $(\boldsymbol{\%})$ \\
\hline Laki-laki & 2178 & 64,45 \\
Perempuan & 1201 & 35,54 \\
Total & 3379 & 100 \\
\hline
\end{tabular}

Tabel 2. Karakteristik populasi menurut umur

\begin{tabular}{ccc}
\hline $\begin{array}{c}\text { Rentang } \\
\text { usia }\end{array}$ & $\begin{array}{c}\text { Jumlah } \\
(\mathbf{n})\end{array}$ & $\mathbf{( \% )}$ \\
\hline 0-28 hari & 37 & 1,09 \\
1-11 bulan & 54 & 1,59 \\
1-4 tahun & 104 & 3,08 \\
5-14 tahun & 301 & 8,91 \\
15-24 tahun & 484 & 14,32 \\
25-44 tahun & 885 & 26,19 \\
45-64 tahun & 1117 & 33,05 \\
>64 tahun & 397 & 11,74 \\
Total & 3379 & 100 \\
\hline
\end{tabular}

Tabel 3. Karakteristik populasi menurut jenis kasus

\begin{tabular}{ccc}
\hline Jenis kasus & $\begin{array}{c}\text { Jumlah } \\
(\mathbf{n})\end{array}$ & $\mathbf{( \% )}$ \\
\hline Trauma & 1009 & 29,86 \\
Non Trauma & 2370 & 70,13 \\
Total & 3379 & 100 \\
\hline
\end{tabular}

\section{BAHASAN}

Pada penelitian ini didapatkan jenis kasus terbanyak yang tercatat di IGD Bedah Prof. Dr. R. D. Kandou Manado pada periode Januari-Desember 2015 yaitu kasus non-trauma $(70,13 \%)$ akan tetapi bila dilihat dari urutan 10 penyakit terbanyak sebagian besar merupakan kasus trauma dan urutan pertama merupakan kasus epidural hematom $(3,55 \%)$. Hal ini tidak sejalan dengan beberapa referensi yang ada antara lain dari data global tercatat kasus yang dihadapi oleh IGD pusat pelayanan kesehatan di berbagai negara kasus trauma cenderung lebih banyak dari kasus non trauma seperti trauma kepala dan cedera otot, tercatat lebih dari 5 juta kasus trauma
Berdasarkan hasil tabulasi data didapatkan 10 kasus terbanyak yang dilakukan penangan bedah gawat darurat. Terbanyak ialah kasus epidural hematom yaitu 120 pasien $(3,55 \%)$ (Tabel 4).

Tabel 4. 10 Besar kasus tercatat di instalasi gawat darurat bedah dengan tindakan bedah pada periode Januari-Desember 2015

\begin{tabular}{|c|c|c|c|}
\hline No & $\begin{array}{c}\text { Diagnosis kasus } \\
\text { (Kode/Kelompok } \\
\text { Kode ICD 10) }\end{array}$ & $\begin{array}{c}\text { Jumlah } \\
\text { pasien }\end{array}$ & $\%$ \\
\hline 1 & $\begin{array}{l}\text { Epidural hematom } \\
\text { (S06.4) }\end{array}$ & 120 & 3,55 \\
\hline 2 & $\begin{array}{l}\text { Subaraknoid } \\
\text { hemorrhage (S06.6) }\end{array}$ & 83 & 2,45 \\
\hline 3 & $\begin{array}{l}\text { Cedera dada dan organ } \\
\text { dalam dada (S20) }\end{array}$ & 66 & 1,95 \\
\hline 4 & $\begin{array}{l}\text { Appendisitis } \\
\text { (K35-K37) }\end{array}$ & 64 & 1,89 \\
\hline 5 & $\begin{array}{l}\text { Fraktur bahu dan } \\
\text { lengan atas (S42) }\end{array}$ & 57 & 1,68 \\
\hline 6 & Sepsis (A41) & 51 & 1,51 \\
\hline 7 & Fraktur femur (S72) & 49 & 1,45 \\
\hline 8 & $\begin{array}{l}\text { Cedera perut dan organ } \\
\text { dalam perut (S30) }\end{array}$ & 48 & 1,43 \\
\hline 9 & Hernia inguinalis (K40) & 40 & 1,18 \\
\hline 10 & $\begin{array}{l}\text { Ileus paralitik dan } \\
\text { obstruksi intestinal } \\
\text { (K56) }\end{array}$ & 38 & 1,12 \\
\hline & Total & 616 & 18,23 \\
\hline
\end{tabular}

pada tahun 2011 di Amerika dan lebih dari 40 juta kasus di Inggris pada periode 20102013. ${ }^{7,9}$ Terdapat referensi dari Jepang yang menyatakan angka kejadian kasus non-trauma tercatat lebih banyak dimana berkisar antara 40-60\% dari keseluruhan kasus kegawatdaruratan pada periode tahun 1965-2008 di negara tersebut. ${ }^{15}$

Di Indonesia sendiri tercatat kasus trauma menduduki peringkat pertama pada kasus bedah dan termasuk sepuluh besar diantara sepuluh penyakit dari seluruh kasus (bedah dan non-bedah) pada tahun 2010 baik yang membutuhkan rawat inap maupun rawat jalan. ${ }^{14,16}$ Angka ini didukung dari sumber yang didapat dari data RSUD Embung Fatimah Kota Batam 
dimana pada tahun 2011 kasus trauma merupakan kasus terbanyak pertama yang tercatat masuk di IGD rumah sakit yaitu kasus vulnus laseratum sebanyak 1778 kasus diikuti dengan beberapa kasus non trauma lainnya. ${ }^{17}$ Juga di beberapa rumah sakit lainnya angka kasus trauma ditemukan cukup besar seperti yang tercatat di UGD RSU Sanglah Denpasar Bali pada tahun 2011 sebanyak 13.149 pasien dan di IGD RSUP dr. Hasan Sadikin Bandung sebanyak 3234 pasien pada tahun yang sama periode Januari-Juli, ${ }^{16,18-19}$ akan tetapi angka ini juga tidak sejalan dengan beberapa sumber lainnya yaitu berdasarkan angka kejadian kasus trauma yang tercatat datang di Instalasi Rawat Darurat (IRD) RSUD dr. Soetomo Surabaya pada tahun 2010 sebesar 1,47\% dari seluruh kunjungan (1.908 kasus). ${ }^{20}$ Perbandingan angka kejadian pada beberapa referensi ini menandakan bahwa distribusi angka kejadian kasus berdasarkan jenis kasus beragam di tiap-tiap pusat pelayanan kesehatan dan diperkirakan dipengaruhi oleh banyak faktor intrinsik maupun ekstrinsik secara langsung maupun tidak langsung seperti geografis, sarana dan tingkat pendidikan. ${ }^{21}$

Karakteristik jenis kelamin terbanyak ialah laki-laki (64,45\%). Temuan ini selaras dengan referensi lain dimana distribusi jenis kelamin laki-laki lebih banyak dari perempuan yang terlihat dari laporan statistik WHO 2016 yaitu dari 475.00 kasus pembunuhan terdapat sekitar 380.00 kasus laki-laki. Demikian pula dari studi yang dilakukan oleh Marin et al. ${ }^{22}$ mendapatkan kasus trauma kepala sebagian besar ialah laki-laki yaitu sebesar 53,92\% (301.574/559.294 kasus) di Amerika pada tahun 2010. ${ }^{22-24} \mathrm{Di}$ Indonesia sendiri didapatkan laki-laki lebih banyak didapatkan pada kasus trauma kecelakaan yaitu sebanyak $59.16 \%$ dari keseluruhan kasus (45.707/77.248 kasus) di Indonesia pada tahun $2007 .^{25}$

Distribusi kasus IGD Bedah yang didominasi oleh laki-laki diperkirakan bergantung dari data masing-masing penyakit spesifik. Angka ini datang dari kasus trauma dan non trauma sehingga dapat diperkirakan faktor-faktor yang memengaruhi perbedaan angka antara jenis kelamin pada masing-masing kasus pun berbeda-beda. Khusus pada kasus trauma laki-laki diperkirakan lebih banyak dari perempuan dimana mayoritas banyak beraktivitas di luar rumah sehingga memiliki risiko yang lebih tinggi dari perempuan. ${ }^{25}$

Rentang usia terbanyak pada penelitian ini ialah 45-64 tahun $(33,05 \%)$. Secara global ditemukan distribusi usia terbanyak ialah pada usia produktif (15-64 tahun). Di Amerika sendiri tercatat kunjungan IGD terbanyak berusia 18-44 tahun (32 juta kasus) dan diikuti oleh rentang usia 1-17 tahun (1.6 juta kasus) dan 45-64 tahun (1.5 juta kasus). ${ }^{7}$ Di Jepang hingga pada tahun 2008 tercatat lebih dari 100 juta kasus (42\%) kegawatdaruratan termasuk dalam rentang umur dewasa. ${ }^{15} \mathrm{Di}$ Indonesia sendiri tercatat khusus untuk kasus trauma kecelakaan didominasi oleh pasien dewasa yaitu sebanyak $56,36 \%$ dari keseluruhan kasus pada tahun $2007 .^{25}$

Distribusi kasus IGD Bedah yang didominasi oleh rentang usia 45-64 tahun diperkirakan dipengaruhi oleh berbagai faktor seperti jenis penyakit dan keadaan, tingkat pendidikan, nutrisi dan lain-lain. Khusus pada kasus trauma tingginya jumlah kasus pada rentang usia dewasa diperkirakan karena pada rentang usia ini tingkat mobilitas tergolong lebih tinggi dengan kelompok usia lainnya. ${ }^{25}$

\section{SIMPULAN}

Berdasarkan hasil penelitian yang dilakukan dapat disimpulkan bahwa distribusi karakteristik kasus terbanyak ialah laki-laki, usia 45-64 tahun, dan kasus non-trauma.

\section{SARAN}

Perlu dilakukan peningkatan kualitas tenaga kesehatan dan fasilitas pelayanan kesehatan khususnya untuk penyakitpenyakit yang paling sering dijumpai.

Perlu edukasi kepada masyarakat tentang faktor-faktor yang dapat 
meningkatkan angka kejadian penyakitpenyakit terkait agar dapat menurunkan angka kejadian.

Perlu dilakukan penelitian lebih lanjut pada tahun-tahun berikutnya untuk perbandingan.

\section{UCAPAN TERIMA KASIH}

Ucapan terima kasih disampaikan kepada Bagian Rekam Medik RSUP Prof. Dr. R. D. Kandou Manado, para staf dan pegawai bagian bedah, serta semua pihak yang telah menyumbang bantuan bagi penulis sehingga penulis dapat menyelesaikan artikel ini.

\section{DAFTAR PUSTAKA}

1. World Health Organization. Definition emergencies. Geneva. 2016. [cited September 3, 2016]. Available from: http://www.who.int/hac/about/definitio ns/en/.

2. Anmwar D. Kamus Lengkap Bahasa Indonesia Dilengkapi dengan: Pedoman Umum Ejaan Bahasa Indonesia yang Disempurnakan. Surabaya: KA, 2001; p. 120,155 .

3. Oh TE. Intensive Care Manual (3rd ed). Australia: Butterworths, 1990; p. 392447, 492-529.

4. Sjamsuhidajat R, Wim DJ. Buku Ajar Ilmu Bedah (2nd ed). Jakarta: EGC, 2003; p. 12-65, 89-117,125-9, 181-92, 208-38, 293-303, 318.

5. Razzak JA, Kellerman AL. Emergency medical care in developing countries: is it worthwhile. Rockville Pike. Bull World Health Organ. 2002;80(11):9005.

6. Pollak AN. Emergency Care and Transportation of the Sick and Injured (10th ed). Massachusetts: Jones \& Bartlett Learning, 2011.

7. Wier MW. Overview of children in the emergency department. Healthcare cost and utilization project. HCUP. Rockville, 2013; p. 157.

8. Centers for Disease Control and Prevention. Emergency department visits and proximity to patients' residences, 2009-2010. 2015. [cited September 1, 2016. Available from: http://www.cdc.gov/nchs/fastats/emerg ency-department.htm.
9. Blunt I. Focus on: a\&e attendances qualitywatch. The Health Foundation; 2014. Nuffieldtrust. 2014.

10. Katayama Y, Kitamura T, Kiyohara K, Iwami T, Kawamura T, Hayashida S, et al. Factors associated with the difficulty in hospital acceptance at the scene by emergency medical service personnel: a population-based study in Osaka City, Japan. BMJ Open. 2016;6:e013849.

11. Persatuan Dokter Spesialis Bedah Umum Indonesia dan Ikatan Ahli Bedah Indonesia. Pedoman nasional pelayanan kedokteran penanganan trauma. Kementrian Kesehatan RI. Jakarta: Kemenkes RI, 2013; p. 1-3, 6-9. ISBN: 978-602-235-294-5.

12. Britt LD, Trunkey DD, Feleciano DV. Acute care surgery principles and practice. New York: Springer, 2007; p. 677-82, 767-96.

13. Uranues $\mathbf{S}$, Lamont $\mathbf{E}$. Acute care surgery the European model. World J Surg. 2008;32(8):1605-12.

14. Sekretariat Pembangunan Kesehatan. Keputusan menteri kesehatan nomor 97 tahun 2015 Kesehatan dalam kerangka sustainable development goals (sdgs) dalam rapat koordinasi pengendalian operasional (Rakorpop) kementrian kesehatan RI. 2015. [cited November 11, 2016]. Available from:

http://www.pusat2.litbang.depkes.go.id /pusat2_v1/wpcontent/uploads/2015/12/SDGs-DitjenBGKIA.pdf.

15. Hori S. Emergency medicine in Japan review. Keio J Med. 2010:59(4);131-9.

16. International Association of Trauma Surgery and Intensive Care. Annual Report, 2009.

17. RSU Daerah Embung Fatimah Kota Batam. Sepuluh penyakit terbanyak instalasi gawat darurat (igd) tahun 2011. 2012. [cited September 2, 2016]. Available from:

http://skpd.batamkota.go.id/rsud/2012/ 04/10/10-penyakit-terbanyak-th-2011igd/. [cited September 2, 2016].

18. IRD RSU Dr. Hasan Sadikin. Laporan kegiatan instalasi rawat darurat rumah sakit. Bandung, 2011.

19. IRD RSU Sanglah. Laporan kegiatan instalasi rawat darurat rumah sakit. 
Denpasar, 2010.

20. IRD RSU Dr. Soetomo. Laporan kegiatan instalasi rawat darurat rumah sakit. Surabaya, 2010.

21. MacKenzei EJ, Fowler CJ. Epidemiology. In: Mattox KL, Feliciano DV, Moore EE, editors. Trauma (6th ed). New York: McGraw Hill, 2008.

22. Marin JR, Weaver MD, Yealy DM, Mannix RC. Trends in visits for traumatic brain injury to emergency departments in the United States. JAMA. 2014;311(18):1917-9.

23. Komisi Trauma Ikatan Ahli Bedah Indonesia. Advanced trauma life support (ATLS) course. Jakarta, 2011.

24. Marx JA, Hockberger RS, Walls RM, et al. Rosen's Emergency Medicine Concepts and Clinical Practice (7th ed). Philadelphia: Elsevier, 2010; p. 2459.

25. Riyadina W, Suhardi, Permana M. Pola dan determinan sosiodemografi cedera akibat kecelakaan lalu lintas di Indonesia. Maj Kedokt Indon. 2009;59:464-72.

26. Riyadina W, Suhardi, Permana M. Pola dan determinan sosiodemografi cedera akibat kecelakaan lalu lintas di Indonesia. Maj Kedokt Indon. 2009;59:464-72. 